\title{
Effects of polycyclic aromatic compounds in fine particulate matter generated from household coal combustion on response to EGFR mutations in vitro ${ }^{\text {th }}$
}

\author{
Kin-Fai Ho ${ }^{\text {a, b, } 1}$, Chih-Cheng Chang ${ }^{\text {c, } 1}$, Linwei Tian ${ }^{\text {d }}$, Chi-Sing Chan ${ }^{\text {a }}$, Benjamin A. Musa Bandowe e, f \\ Ka-Hei Lui ${ }^{a}$, Kang-Yun Lee ${ }^{\text {c, g }}$, Kai-Jen Chuang ${ }^{\text {h, i }}$, Chien-Ying Liu ${ }^{\mathrm{j}, \mathrm{k}}$, Zhi Ning ${ }^{1}$, Hsiao-Chi Chuang ${ }^{\text {c, g, m, * }}$ \\ a Jockey Club School of Public Health and Primary Care, The Chinese University of Hong Kong, Hong Kong \\ ${ }^{\mathrm{b}}$ Shenzhen Municipal Key Laboratory for Health Risk Analysis, Shenzhen Research Institute, The Chinese University of Hong Kong, Shenzhen, China \\ ${ }^{c}$ Division of Pulmonary Medicine, Department of Internal Medicine, Shuang Ho Hospital, Taipei Medical University, New Taipei City, Taiwan \\ ${ }^{\mathrm{d}}$ School of Public Health, The University of Hong Kong, Hong Kong \\ e Institute of Geography, University of Bern, Hallerstrasse 12, 3012 Bern, Switzerland \\ ${ }^{\mathrm{f}}$ Oeschger Centre for Climate Change Research, University of Bern, Falkenplatz 16, 3012 Bern, Switzerland \\ ${ }^{g}$ Department of Internal Medicine, School of Medicine, College of Medicine, Taipei Medical University, Taipei, Taiwan \\ ${ }^{\mathrm{h}}$ Department of Public Health, School of Medicine, College of Medicine, Taipei Medical University, Taipei, Taiwan \\ ${ }^{i}$ School of Public Health, College of Public Health and Nutrition, Taipei Medical University, Taipei, Taiwan \\ j Department of Thoracic Medicine, Chang Gung Memorial Hospital, Chang Gung University School of Medicine, Taipei, Taiwan \\ ${ }^{\mathrm{k}}$ Department of Thoracic Medicine, Division of Oncology and Interventional Bronchoscopy, Chang Gung Memorial Hospital, Taipei, Taiwan \\ ${ }^{1}$ School of Energy and Environment, City University of Hong Kong, Hong Kong \\ ${ }^{\mathrm{m}}$ School of Respiratory Therapy, College of Medicine, Taipei Medical University, Taipei, Taiwan
}

\section{A R T I C L E IN F O}

\section{Article history:}

Received 18 May 2016

Received in revised form 30 August 2016

Accepted 30 August 2016

Available online xxx

\section{Keywords:}

Coal combustion

Lung cancer

Polycyclic aromatic compounds

Xuanwei

\section{A B S T R A C T}

Induction of $\mathrm{PM}_{2.5}$-associated lung cancer in response to $E G F R$-tyrosine kinase inhibitors (EGFR-TKI) remains unclear. Polycyclic aromatic hydrocarbons (PAHs) and their polar derivatives (oxygenated PAHs: OPAHs and azaarenes: AZAs) were characterized in fine particulates $\left(\mathrm{PM}_{2.5}\right)$ emitted from indoor coal combustion. Samples were collected in Xuanwei (Yunnan Province), a region in China with a high rate of lung cancer. Human lung adenocarcinoma cells A549 (with wild-type $E G F R$ ) and HCC827 (with EGFR mutation) were exposed to the $\mathrm{PM}_{2.5}$, followed by treatment with EGFR-TKI. Two samples showed significant and dose-dependent reduction in the cell viability in A549. EGFR-TKI further demonstrated significantly decreased in cell viability in A549 after exposure to the coal emissions. Chrysene and triphenylene, dibenzo $[a, h]$ anthracene, benzo[ghi]perylene, azaarenes and oxygenated polycyclic aromatic hydrocarbons (carbonyl-OPAHs) were all associated with EGFR-TKI-dependent reduced cell viability after 72-h exposure to the $\mathrm{PM}_{2.5}$. The findings suggest the coal emissions could influence the response of EGFR-TKI in lung cancer cells in Xuanwei. The $\mathrm{PM}_{25}$ emitted from coal combustion shows association with EGFR-TKI response in vitro, which the association can be further linked with chrysene and triphenylene, dibenzo $[a, h]$ anthracene, benzo[ghi]perylene, azaarenes and oxygenated PAHs.

(C) 2016 Published by Elsevier Ltd.

\section{Introduction}

Lung cancer is malignant tumor due to uncontrolled cell growth in lung tissues and a leading cause of cancer mortality. Lung carcinoma is the second most common cancer in men and women at the United States (CDC, 2015). Cigarette smoking is identified to be the most common etiological risk factor for lung cancer, contributing in about

\footnotetext{
This paper has been recommended for acceptance by David Carpenter.

* Corresponding author. Taiwan CardioPulmonary Research (T-CPR) Group, School of Respiratory Therapy, College of Medicine, Taipei Medical University, 250 Wuxing Street, Taipei 110, Taiwan.

Email address: r92841005@ntu.edu.tw (H-C Chuang)

1 These authors contributed equally to the study.
}

$85 \%$ of patients at the United States and Europe (Dela Cruz et al., 2011). Nonetheless, non-smoking women in Xuanwei, China exhibited unusually high lung cancer rates (Chen et al., 2015; Hosgood et al., 2013; Mumford et al., 1995). Clinical and pathological evidences suggested risk factors for lung cancers in non-smokers were distinctive from smoking-related lung cancers, particularly adenocarcinoma (Molina et al., 2008). Xuanwei is renowned for studying lung cancer and environmental risk factors related research due to its recorded highest lung cancer in women, and the majority of those are non-smokers (Chen et al., 2015). Domestic fuel combustion, such as indoor coal burning, was considered to be a risk factor in previous studies (Barone-Adesi et al., 2012; Hosgood et al., 2013); however, the actual inducing factor could be somewhat different (e.g. by-products in the coal combustion). A past study showed mutations in the epidermal growth factor receptor $(E G F R)$ gene were associated with lung cancer prevalence in non-smoking women at Xuanwei (Hosgood 
et al., 2013). Mutations in EGFR exons 18 and 21 are recognized to be sensitive to emissions from coal combustion (Hosgood et al., 2013). Lung cancer patients with EGFR mutations show effective response to $E G F R$-tyrosine kinase inhibitors (EGFR-TKIs) (Chen et al., 2010), whereas lung cancer patients with mutation in the Kirsten rat sarcoma viral oncogene homolog gene (KRAS) demonstrate inferior response to EGFR-TKI (Langer, 2011). Arrieta et al. (2008) observed the lung cancer patients with history of exposure to biomass burning exhibited positive response to EGFR-TKIs and improved progression-free survival (Arrieta et al., 2008). Coal combustion emits polycyclic aromatic compounds (PACs), such as polycyclic aromatic hydrocarbons (PAHs), oxygenated PAHs (OPAHs) and nitrogen heterocyclic polycyclic aromatic compounds (azaarenes), which are all considered to be toxic, mutagenic, and carcinogenic (IARC, 2010; Simoneit et al., 2007). Pulmonary exposure to PAHs could increase lung cancer prevalence in China by 1.6 times (Wang et al., 2012; Zhang et al., 2009). The objectives of this study were to investigate the effects of $\mathrm{PM}_{2.5}$ emitted from coal combustion on EGFR-TKI response in vitro and evaluate the relationships between $\mathrm{PM}_{2.5}$-bound PACs and EGFR-TKI response.

\section{Materials and methods}

\subsection{Coal combustion}

Coal combustion experiments were conducted in an un-connected, single room located at Shangzuosuo village in Xuanwei County, Qujing, Yunnan Province, China, between November 2012 and January 2013. The room volume was approximately $42.6 \mathrm{~m}^{3}$ (5.9 $\mathrm{m}$ long, $3.8 \mathrm{~m}$ wide and $1.9 \mathrm{~m}$ high). The air change rate in the room was monitored continuously by measuring the first order carbon dioxide decay using a Q-Trak ${ }^{\mathrm{TM}}$ indoor air quality monitor (model 8550; TSI Inc., Shoreview, MN, USA) installed in the kitchen area in the room. The air change was set as $6.9 \mathrm{~h}^{-1}$. All doors and windows in the living room were fastened during the experiment.

A laboratory stove (with internal diameter of $15 \mathrm{~cm}$ ) was used to simulate the firepits used for coal-burning activities in daily basis. The stove mass, biomass (containing dried sugar cane and corn stock for fire purpose), and masses of coal samples were all measured to maintain consistency throughout the experiment. The coal samples in a range of $0.5-4 \mathrm{~kg}$ was used for each combustion process. Large coal samples were harmonized to a size range of $4-8 \mathrm{~cm}$ in diameter in order to facilitate combustion.

Four types of coal samples (DSFZK9, DSFZK3, ZJB3, and YTB2) were combusted, and the air particulate matter was simultaneously collected. Four types of coal were tested for emissions. The samples were labeled A-D and were collected from different locations, Dongshan (K9) (Latitude: 26.143951, Longitude: 104.150282) Zhaojiachong (B3) (Latitude: 26.435658, Longitude: 104.26772), Dongshan (K3) (Latitude: 26.143951, Longitude: 104.150282), and Laibin (B2) (Latitude: 26.3153292, Longitude: 104.1591844), in Xuanwei. The coal seams from which the samples were collected are denoted in parentheses. Each coal sample was combusted in triplicates. Small amount of biomass material was added with the aid of setting fire in outdoor environment, in addition with using a blower and chimney to ensure kindling. The air was purged through the stove inlet to supply oxygen for combustion, and the chimney was located on top of the stove to enhance stack effect. After full kindling (approximately $5 \mathrm{~min}$ after the initial ignition), approximately $2 \mathrm{~kg}$ of coal samples were added to the stove. Ten minutes from the initial ignition, the remaining coal samples were also added. The stove was immediately transferred to the kitchen and positioned on a balance. The weight of the stove included with the coal samples was recorded. All biomass materials were completely removed from the stove at outdoor prior to extinguish the fire. A pot containing $2 \mathrm{~kg}$ of water at room temperature was placed above the stove. Coal lumps melted and coagulated during combustion, which could extinguish the fire. To simulate cooking practices, the fire was stroked and poked to ensure efficient air ventilation through the coal lumps in every 20 min during combustion. More coal was added to the stove in every $20 \mathrm{~min}$. Water was heated up to boiling point during the heating process. The complete heating process required 30-60 min depending on different types of coal. The ashes were weighed after each combustion cycle. The combustion cycle was consistent with household coal-burning activities typically used in Xuanwei (approximately $1 \mathrm{~h}$ ). The fire was re-used for experiments with the same type of coal. Before switching samples, the fire was extinguished using a water sprayer. The weight of the coal and water was recorded in every 10 min during the experiment.

\section{2. $P M_{2.5}$ sampling}

Two mini-volume portable air samplers with program function (Mini-vol, Airmetrics, Eugene, OR, USA) operating at uniform flow rates of $5 \mathrm{~L} / \mathrm{min}$ were used to collect particulate matter (PM) samples (from air originating from stove) during the coal combustion cycle. The samples were collected on $47 \mathrm{~mm}$-diameter quartz microfiber filters (for chemical analyses) and Teflon membranes (for bioreactivity), which were separately loaded in a PM less than $2.5 \mu \mathrm{m}\left(\mathrm{PM}_{2.5}\right)$ inlet cassette on the Mini-vol. The air was purged through a $\mathrm{PM}_{10}$ impactor, and the coarse particles were filtered; subsequently, particulate matters $>\mathrm{PM}_{2.5}$ were filtered through a $\mathrm{PM}_{2.5}$ impactor and loaded on filter substrates. The filters were fully loaded in short time due to high amount of smoke emitted during combustion.

\subsection{Analyses of polycyclic aromatic compounds}

The concentrations of 29 PAHs and 17 oxygen-containing polycyclic aromatic hydrocarbons (OPAHs) and 3 azaarenes (Table S1) were determined for each filter. Filters were cut in small pieces, transferred in a $33 \mathrm{~mL}$-accelerated solvent extractor (ASE) cell, and spiked with $100 \mu \mathrm{L}$ of mixture of 7 deuterated-PAHs $(10 \mu \mathrm{g} / \mathrm{mL}$ naphthalene-D8, acenaphthene-D8, phenanthrene-D10, pyrene-D10, chrysene-D12 benzo[ghi]perylene-D12 each), $50 \mu \mathrm{L}$ of 2 deuterated-OPA $(20 \mu \mathrm{g} / \mathrm{mL}$ each of benzophenone-D5, 9,10-anthraquinone-D8), 2-naphthol-D7 $(20 \mu \mathrm{g} / \mathrm{mL})$, and carbazole-D8 $(20 \mu \mathrm{g} / \mathrm{mL})$ as the internal standard for PAHs, carbonyl-OPAHs, hydroxyl/carboxyl-OPAHs and azaarenes, respectively. The remaining spaces within each ASE cell were filled with inert bulk solvent (Isolute HMN, Biotage, Uppsala, Sweden). Each sample was extracted twice by pressurized liquid extraction using an accelerated solvent extractor (ASE 200, Dionex, and Sunnyvale, CA, USA). Dichloromethane was used as solvent for the first extraction, and a mixture of acetone: dichloromethane $(2: 1 \mathrm{v} / \mathrm{v})$ was used for the second extraction. The instrument conditions of ASE were the same as specified elsewhere (Bandowe and Wilcke, 2010). The two extracts obtained from each sample were combined; $15 \mathrm{~mL}$ of hexane was added and concentrated to a volume $<1 \mathrm{~mL}$ using a TurboVap II Concentrator Workstation (Biotage, Charlotte, NC, USA) operating at a water bath temperature of $35^{\circ} \mathrm{P}$ ssurized with $\mathrm{N}_{2}$ gas at pressure of 15 Psi. Each extract was the nsferred unto a column containing $3 \mathrm{~g}$ (10\% deactivated silica gel). Target compounds from each column was eluted sequentially with $15 \mathrm{~mL}$ hexane: dichloromethane 
$(5: 1 \mathrm{v} / \mathrm{v})$, followed by $8 \mathrm{~mL}$ dichloromethane, and $5 \mathrm{~mL}$ acetone. The eluates were collected in flasks, spiked with a few drops of toluene (as keeper), rotary evaporated to $<1 \mathrm{~mL}$ volume. Each extract was then transferred into $2 \mathrm{~mL}$ GC-vials after spiking $50 \mu \mathrm{L}$ of fluoranthene-D10 $(22 \mu \mathrm{g} / \mathrm{mL}$ as recovery standard). PACs in extracts of samples, blanks and calibration standards were measured with a gas chromatograph (GC: $7890 \mathrm{~N}$, Agilent) coupled to a mass spectrometer (MS: 5975 C, Agilent, Santa Clara, CA, USA). PAHs, carbonyl-OPAHs/azaarenes and hydroxyl/carboxyl-OPAHs were measured in separate runs using GC-MS procedures as previously specified. Hydroxyl and carboxyl-OPAHs were first derivatized with BSTFA: TMCS $(99: 1 \mathrm{v} / \mathrm{v})$ before GC-MS measurements (Bandowe and Wilcke, 2010; Bandowe et al., 2014). Further details of the instrumental specifications of the GC-MS system, target, and qualifier ions for each compound were the same as specified in the literature (Bandowe and Wilcke, 2010). GC-MS data were recorded and processed using Agilent ChemStation software. The internal standard quantification procedure was adopted to set up calibration curves and quantified compound concentrations in all samples and blanks.

Several quality control and assurance measures were applied throughout the PAC analyses. High purity (HPLC grade) solvents were used for all extractions, rinsing, and preparation of standards. Laboratory glassware, metal ware and metallic parts of the ASE extraction cells and were washed with a washing machine, and baked in an oven $250^{\circ} \mathrm{C}$ (for $24 \mathrm{~h}$ ) before being used. Glassware was further rinsed with high purity HPLC grade solvents immediately before use. Blanks made of inert bulk sorbent (Isolute HMN, Biotage, Uppsala, Sweden) were extracted and their PACs content analyzed together with the real samples. The target PACs were frequently not detected in the blanks or when detected only at trace levels. Under detection, the average masses were deducted from the mass of the target compound in the real samples before calculating the concentrations. The mass of target compound that was higher than the baseline noise by a factor of $3(\mathrm{~S} / \mathrm{N}=3)$ is defined as the limit of detection (LOD). Masses of target compounds in extracts of samples that were below the LOD were denoted as "non-detected (N.D.)".

\subsection{Cell culture}

Human lung adenocarcinoma cells A549 (with wild-type EGFR) and HCC827 (with EGFR mutation) obtained from the American Type Culture Collection (ATCC, Manassas, VA, USA) were seeded in surface-treated, 96-well transwells at a density of $1 \times 10^{5}$ cells $/ \mathrm{mL}$ and incubated for $24 \mathrm{~h}$ (BD Biosciences, Oxford, UK). The cells were cultured in RPMI containing 10\% fetal bovine serum, penicillin and streptomycin and were incubated under $37{ }^{\circ} \mathrm{C}, 95 \%$ humidity, and $5 \%$ $\mathrm{CO}_{2}$.

\subsection{Experimental designs}

Methanol-PM $\mathrm{PM}_{2.5}$ extracts were performed as described previously using two stages sonication in methanol (Chuang et al., 2013). The extracts were dried using sterile nitrogen stream and reconstituted using dimethyl sulphoxide $(<0.01 \%$ volume $)$ in RPMI. The samples were stored at $4{ }^{\circ} \mathrm{C}$ and used within one week after the preparation. The three experimental designs used in this study are shown in Fig. 1.
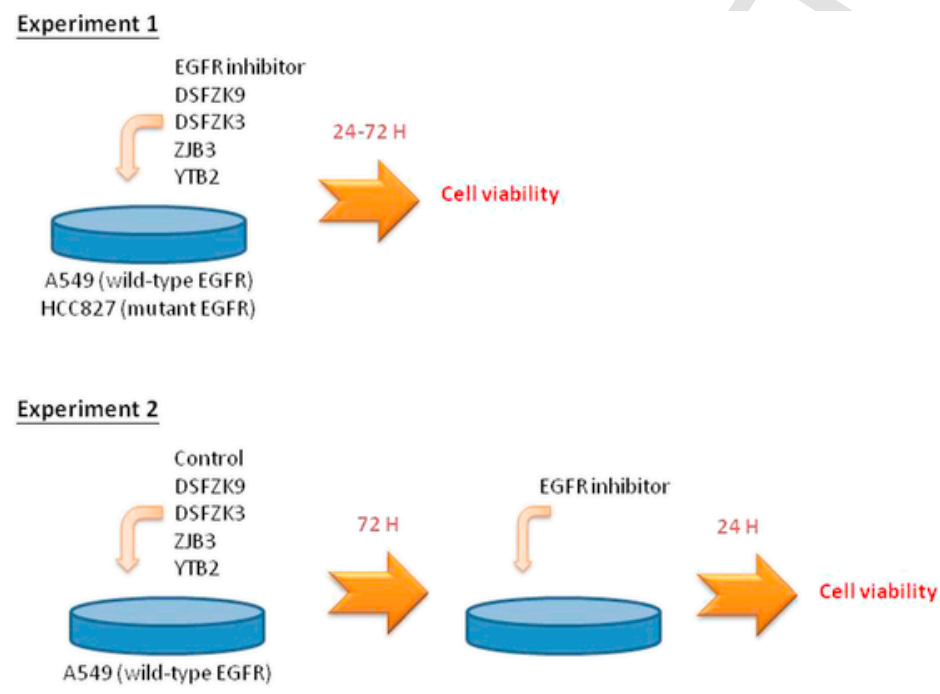

Experiment 3
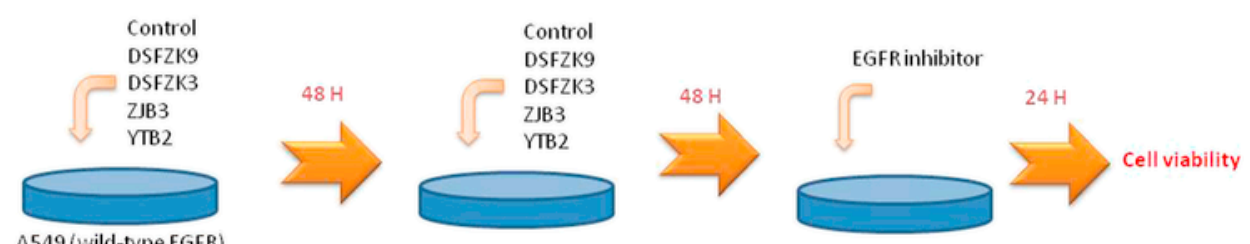

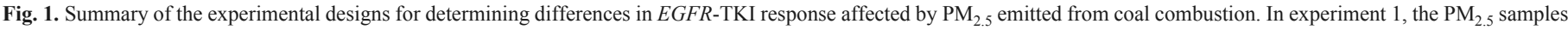

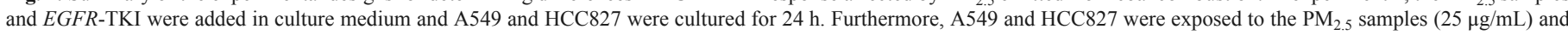

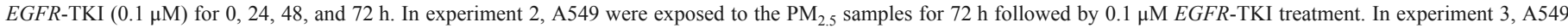
were exposed to the $\mathrm{PM}_{2.5}$ samples for $48 \mathrm{~h}$ twice, followed by $0.1 \mu \mathrm{M} E G F R$-TKI treatment. Each experiment was sextuplicated. 
In experiment 1, A549 and HCC827 were treated for $24 \mathrm{~h}$ with $200 \mu \mathrm{L}$ of the $\mathrm{PM}_{2.5}$ samples at $0,6.25,12.5,25,50$, and $100 \mu \mathrm{g} / \mathrm{mL}$ and EGFR-TKI (Iressa; Tocris Bioscience, Bristol, UK) at 0, 0.0001, $0.001,0.01,0.1,1,2,5$, and $10 \mu \mathrm{M}$. To evaluate the time-dependent response, A549 and $\mathrm{HCC} 827$ were treated with $200 \mu \mathrm{L}$ of the $\mathrm{PM}_{2.5}$ samples at $25 \mu \mathrm{g} / \mathrm{mL}$ and EGFR-TKI at $0.1 \mu \mathrm{M}$ for $0,24,48$, and $72 \mathrm{~h}$. In experiment 2, A549 were treated with $200 \mu \mathrm{L}$ of the $\mathrm{PM}_{2.5}$ samples at 0 (control) and $25 \mu \mathrm{g} / \mathrm{mL}$ for $72 \mathrm{~h}$. After the cells regrew to confluency, $0.1 \mu \mathrm{M} E G F R$-TKI was added to the culture medium, and the cells were incubated for an additional $24 \mathrm{~h}$. In experiment 3, A549 was treated with $200 \mu \mathrm{L}$ of the $\mathrm{PM}_{2.5}$ samples at 0 (control) and $25 \mu \mathrm{g} / \mathrm{mL}$ for $48 \mathrm{~h}$. After the cells regrew to confluency, 48-h exposures of 0 (control) and $25 \mu \mathrm{g} / \mathrm{mL} \mathrm{PM}_{2.5}$ samples were repeated. After the cells regrew to confluency, $0.1 \mu \mathrm{M} E G F R$-TKI was added to the culture medium, and the cells were incubated for an additional $24 \mathrm{~h}$. Each experiment was sextuplicated. Concentrations of $\mathrm{PM}_{2.5}$ that produced $50 \%$ cell death were chosen.

\subsection{Cell viability}

A sulforhodamine B colorimetric assay was used for determining cell viability according to a previously established method (Vichai and Kirtikara, 2006). Briefly, cells were fixed with $10 \%(\mathrm{w} / \mathrm{v})$ trichloroacetic acid and stained for $30 \mathrm{~min}$. The protein-bound dye was dissolved in a $10 \mathrm{mM}$ Tris-base solution after removing the excess dye, and optical density (OD) was measured at $510 \mathrm{~nm}$ using a microplate reader. Cell viability was presented in percentage after adjustment for the control.

\subsection{Statistical analyses}

Statistical analyses were performed using GraphPad Version 5 for Windows. The Shapiro-Wilk test was used to test for normality. For comparing multiple values, one-way analysis of variance (ANOVA) and the Tukey post hoc test was used. Spearman correlation coefficient was applied for examining the correlation of cell viability after 72-h and two 48-h exposures to chemical levels (ng PACs/ $\mu g$ PM). $P<0.05$ was considered significant.

\section{Results}

\subsection{Characterization of $P A C s$ in emitted $P M_{2.5}$}

Table 1 summarizes the concentration of 29 PAHs, 4 hydroxylor carboxyl-OPAHs, 13 carbonyl-OPAHs, and 3 azaarenes bound to $\mathrm{PM}_{2.5}$ emitted from the combustion of 4 types of coal samples (DSFZK9, DSFZK3, ZJB3, and YTB3). Further details of these chemical compounds are listed in the supplementary materials Table S2.

The average concentration of the $\sum \mathrm{PAHs}$ in $\mathrm{PM}_{2.5}$ emitted from the 4 types of coal was $282,003 \mathrm{ng} / \mathrm{m}^{3}$ (range: 153,730-375,722).
The highest concentration is in DSFZK9 and lowest in DSEZK3. The most abundant PAHs in the $\mathrm{PM}_{2.5}$ samples were phenanthrene, 1-methylphenanthrene, pyrene, benzo $[a]$ anthracene, benzo $[b+j+k]$ fluoranthene, benzo $[e]$ pyrene, benzo $[a]$ pyrene, and benzo[ghi]perylene. The highest concentration of the $\sum$ hydroxyl + carboxyl-OPAHs was in YTB2 $\left(23,943 \mathrm{ng} / \mathrm{m}^{3}\right)$ and lowest in DSFZK3 $\left(8381 \mathrm{ng} / \mathrm{m}^{3}\right)$. 2-Napthol was the most abundant hydroxyl/ carboxyl-OPAH compound in all samples. The average concentration of the $\sum$ carbonyl-OPAHs was $53,352 \mathrm{ng} / \mathrm{m}^{3}$, with the highest and lowest concentrations identified to be in YTB3 and DSFZK3 respectively. The carbonyl-OPAHs mixtures were dominated by 9-fluorenone, 9,10-anthraquinone, and 7H-benz[e]anthracene-7-one. The concentrations of $\sum$ azaarenes averaged in $26,494 \mathrm{ng} / \mathrm{m}^{3}$ with the highest and lowest reported to be YTB3 and DSFZK3, respectively. The most abundant component in azaarenes mixtures was carbazole.

\subsection{Cell viability after $P M_{2.5}$ exposure (experiment 1)}

The three experimental designs used in this study are shown in Fig. 1. In the present study, A549 with wild-type EGFR and HCC827 with $E G F R$ mutation were used. First, EGFR-TKI and $\mathrm{PM}_{2.5}$ emitted from the four types of coal samples were added in the culture medium and cultured for $24 \mathrm{~h}$ (Fig. 2a). HCC 827 were more sensitive to EGFR-TKI than A549, which caused $49 \%$ reduction in cell viability at $0.1 \mu \mathrm{M}$ EGFR-TKI. Cell viability in A549 and HCC827 showed significantly decreased dose-dependently. $\mathrm{PM}_{2.5}$ emitted from the ZJB3 and YTB2 samples showed significantly reduced cell viability in both types of cells, specifically at $\geq 12.5 \mu \mathrm{g} / \mathrm{mL}(P<0.05)$, compared with reduction caused by $\mathrm{PM}_{2.5}$ emitted from the DSFZK9 and DSFZK3 samples.

The time-dependent response of cell viability after exposures to $0.1 \mu \mathrm{M} E G F R$-TKI and $25 \mu \mathrm{g} / \mathrm{mL} \mathrm{PM}_{2.5}$ are shown in Fig. $2 \mathrm{~b}$. EGFR-TKI substantially reduced cell viability in HCC 827 after $48 \mathrm{~h}$ of exposure (13.5\%), whereas cell viability decreased by $49.7 \%$ in A549 after exposure for the same duration. Cell viability significantly reduced in the $\mathrm{HCC} 827$ after $24 \mathrm{~h}$ of exposure to $\mathrm{PM}_{2.5}$ emitted from the ZJB3 and YTB2 samples compared with the reduction in A549 exposed for the same duration to $\mathrm{PM}_{2.5}$ emitted from the DSFZK9 and DSFZK3 samples $(P<0.05)$; however, no significant difference was observed in the reduction of cell viability after 72-h exposure to $\mathrm{PM}_{2.5}$ emitted from the four coal samples. Due to the decrease in cell viability caused by the $\mathrm{PM}_{2.5}$ in $\mathrm{HCC} 827$, the repeat exposure experiment following $E G F R$-TKI treatment was not conducted.

\subsection{Cell viability after $72 \mathrm{~h}$ exposure to emissions from the $P M_{2.5}$ samples in response to EGFR-TKI (experiment 2)}

To investigate the effects of $\mathrm{PM}_{2.5}$ exposure on the EGFR-TKI treated cells, A549 were incubated for $72 \mathrm{~h}$ with the four $\mathrm{PM}_{2.5}$ sam-

Table 1

Concentration $\left[\mathrm{ng} \mathrm{m}^{-3}\right.$ ] of polycyclic aromatic compounds bound to $\mathrm{PM}_{2.5}$ emitted from the four types of coal that are commonly used in Xuanwei, China.

\begin{tabular}{|c|c|c|c|c|}
\hline Sum of PAC group & DSFZK 9 & DSFZK3 & ZJB3 & YTB2 \\
\hline$\sum 29 \mathrm{PAHs}$ & $375,722 \pm 150132$ & $153,730 \pm 39828$ & $236,463 \pm 99275$ & $362,095 \pm 59473$ \\
\hline$\sum$ Hydroxyl + Carboxyl-OPAHs & $17,732 \pm 11151$ & $8381 \pm 9273$ & $10,061 \pm 3258$ & $23,943 \pm 10000$ \\
\hline $\bar{\Sigma}$ Carbonyl-OPAHs & $64,439 \pm 31014$ & $25,281 \pm 8279$ & $36,860 \pm 17604$ & $86,826 \pm 12958$ \\
\hline $\bar{\sum}$ Azaarenes & $34,201 \pm 18019$ & $13,060 \pm 5062$ & $18,451 \pm 8765$ & $40,263 \pm 11610$ \\
\hline
\end{tabular}

ND: non-detected. 
(a)
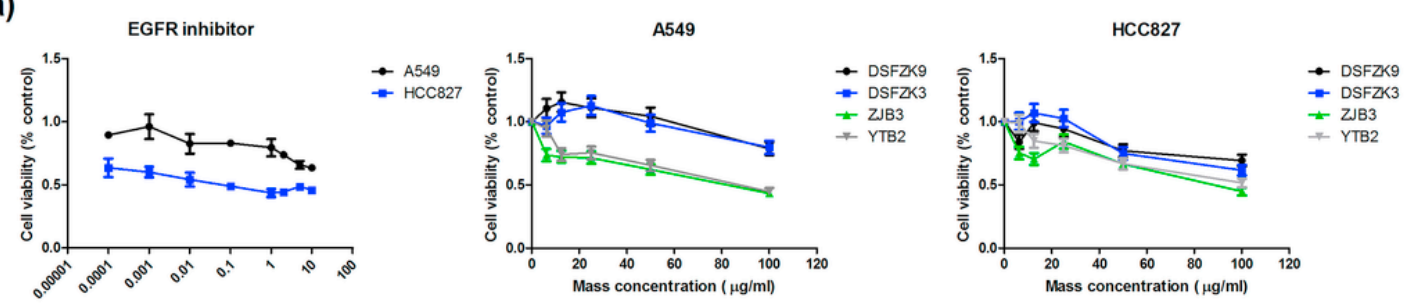

(b)
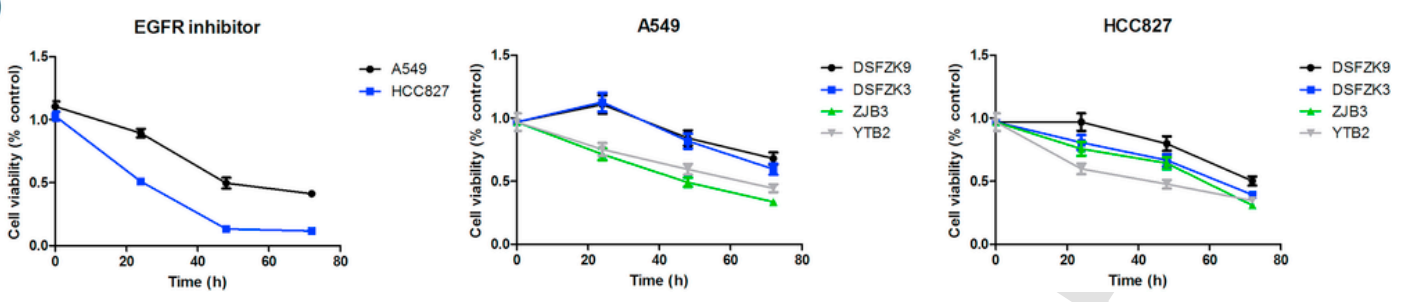

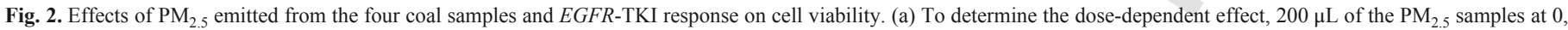

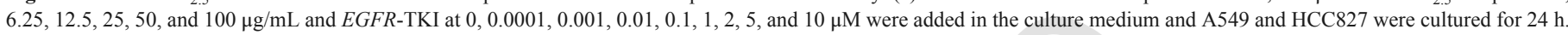

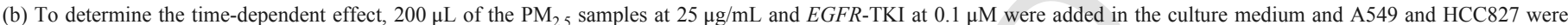
cultured for $0,24,48$, and $72 \mathrm{~h}$.

ples at a concentration of $25 \mu \mathrm{g} / \mathrm{mL}$ following 24-h incubation with $0.1 \mu \mathrm{M} E G F R$-TKI; the cell viability data are presented in Fig. 3a. We observed that the decrease in cell viability after EGFR-TKI treatment in the cells exposed to $\mathrm{PM}_{2.5}$ emitted from the DSFZK9 sample was significantly less $(38 \% \pm 6 \% ; P<0.05)$, whereas the EGFR-TKI treated cells exposed to $\mathrm{PM}_{2.5}$ emitted from the ZJB3 sample $(114 \% \pm 10 \% ; P<0.05)$ was significantly high. Exposures of $\mathrm{PM}_{2.5}$ emitted from the DSFZK3 $(88 \% \pm 6 \%)$ and YTB2 $(85 \% \pm 17 \%)$ samples for $72 \mathrm{~h}$ had no significant effects on cell viability after EGFR-TKI treatment.

3.4. Cell viability after two 48-h exposures to $P M_{2.5}$ in response to EGFR-TKI (experiment 3)

To determine the effect of repeated exposure to $\mathrm{PM}_{2.5}$ emitted from the four coal samples on EGFR-TKI treated cells, A549 were incubated with $\mathrm{PM}_{2.5}$ emitted from the four samples at a concentration of $25 \mu \mathrm{g} / \mathrm{mL}$ for $48 \mathrm{~h}$ following 24-h incubation with $0.1 \mu \mathrm{M}$ EGFR-TKI. PM $_{2.5}$ emitted from all DSFZK9, DSFZK3, ZJB3, and YTB2 samples significantly $(P<0.05)$ reduced cell viability after EGFR-TKI treatment, which were $47 \% \pm 9 \%, \quad 40 \% \pm 4 \%$, $46 \% \pm 5 \%$, and $44 \% \pm 6 \%$, respectively (Fig. $3 \mathrm{~b}$ ).

\subsection{Associations between PAHs, hydroxyl-or carboxyl-OPAHs, azaarenes, and carbony-OPAHs and cell viability}

Associations between PAHs, hydroxyl- or carboxyl-OPAHs, azaarenes, and carbonyl-OPAHs and cell viability in cells exposed to $\mathrm{PM}_{2.5}$ emitted from the 4 coal samples for $72 \mathrm{~h}$ and repeated $48 \mathrm{~h}$ are shown in Fig. 4. Firstly, the probable human carcinogens indicated by the USEPA (shown in Table S2) were correlated to the cell viability after 72-h and twice 48-h exposure (Fig. 4a). Chrysene and tripheny- (a)

72-h exposure following 24-h EGFR inhibitor

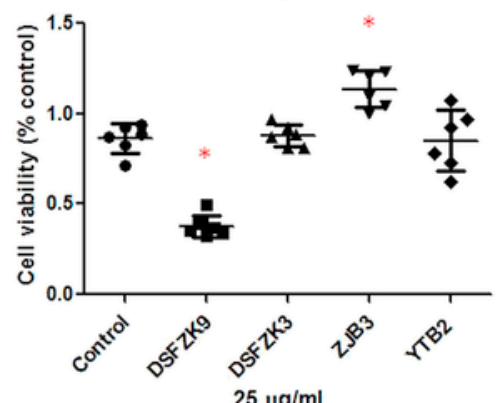

(b)

\section{Twice 48-h exposure following 24-h EGFR inhibitor}

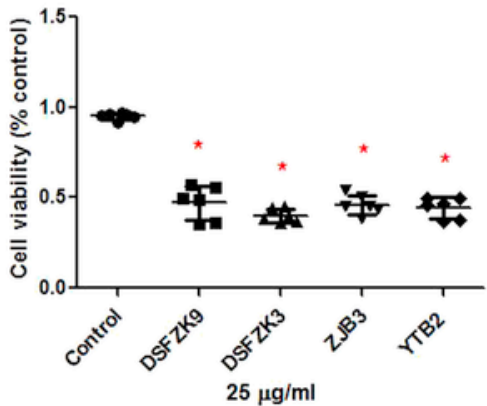

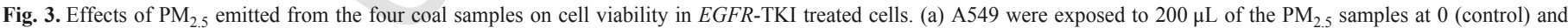

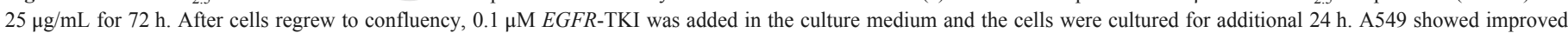

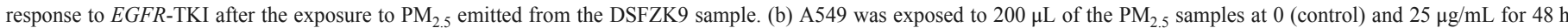

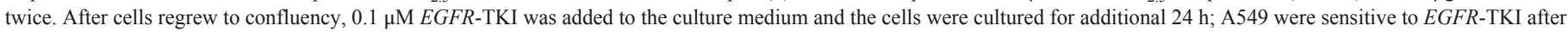
this treatment. 
(a)

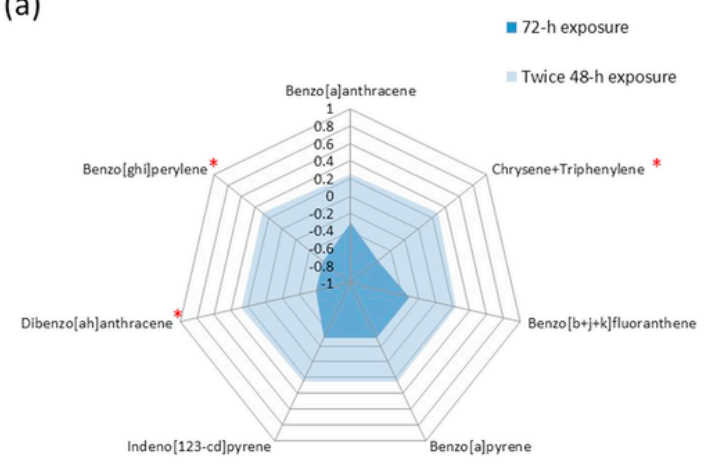

(b)

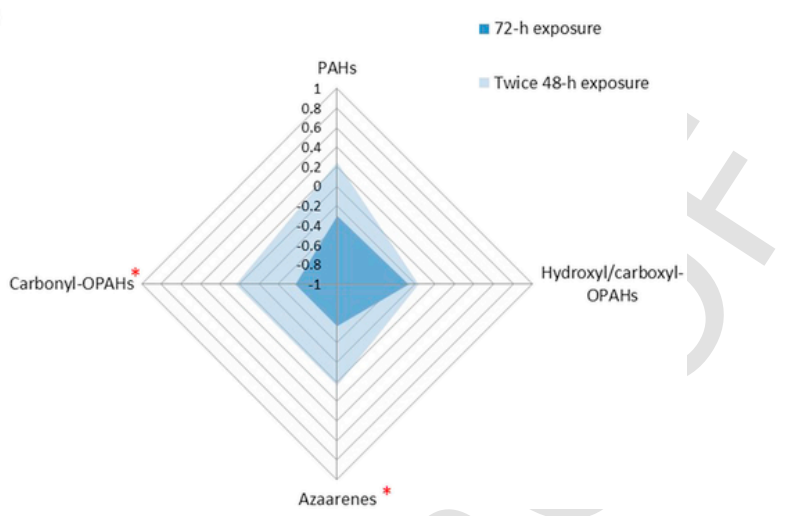

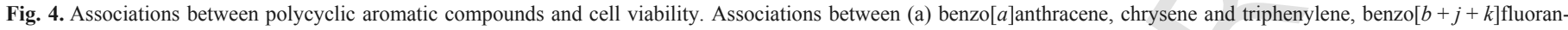

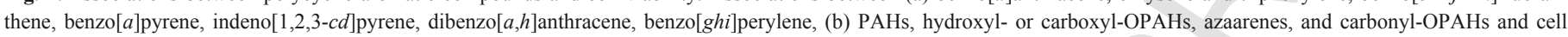

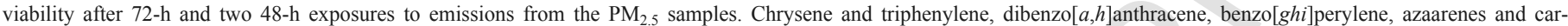
bonyl-OPAHs were negatively correlated to cell viability after 72-h exposure.

lene, dibenzo $[a, h]$ anthracene and benzo[ghi]perylene were negatively correlated to cell viability after 72 -h exposure $(P<0.05)$, but not in twice 48 -h exposure. The $\sum$ azaarenes and $\sum$ carbonyl-OPAHs were also negatively correlated to cell viability after 72-h exposure (Fig. $4 \mathrm{~b}$; correlation coefficient of $-0.57 ; P<0.05$ for both). Total PAHs and hydroxyl- or carboxyl-OPAHs were not correlated with cell viability after 72-h exposure. In addition, PAHs, hydroxyl- or carboxyl-OPAHs, azaarenes, and carbonyl-OPAHs were not correlated to cell viability after two 48-h exposures.

\section{Discussion}

Mutations in EGFR are linked to pulmonary exposure to $\mathrm{PM}_{2.5}$ emitted from coal combustion; however, biological evidence identifying relevant environmental factors for lung cancer are scarce. In this study, we propose that $\mathrm{PM}_{2.5}$ emitted from coal combustion was associated with EGFR-TKI response in vitro. Three major findings are reported in the present study: (1) $\mathrm{PM}_{2.5}$ emitted from two types of coal significantly and dose-dependently reduced cell viability in A549, (2) cell viability in $\mathrm{A} 549$ exposed to four $\mathrm{PM}_{2.5}$ samples significantly decreased and (3) Chrysene and triphenylene, dibenzo[ $[a, h]$ anthracene, benzo[ghi]perylene, azaarenes and carbonyl-OPAHs were associated with a decrease in cell viability after 72-h exposure to the $\mathrm{PM}_{2.5}$ samples followed by EGFR-TKI treatment.

Coal is commonly used as fuel for domestic purposes worldwide; however, coal combustion increases levels of $\mathrm{PM}_{2.5}$ in indoor environment. Shao et al. (2016) have demonstrated that raw coal compositions had good correlation with the biological effects of coal burnt particles (Shao et al., 2016). Previous studies showed that PM emitted from coal combustion contained significant amount of known carcinogens and mutagens, such as PAHs, OPAHs and azaarenes (Bi et al., 2008; Liu et al., 2015). Notably, Lan et al. (2008) have shown that the lung cancer risks in Xuanwei were associated with the use of bituminous coal (as opposed to anthracite coal), suggesting the types of coal samples (such as bituminous coal) might result in geographical variation in lung cancer incidence (Lan et al., 2008; Shao et al., 2013). The four types of coals samples (DSFZK9, DSFZK3, ZJB3, and YTB2) obtained from difference areas are commonly used in Xuanwei, China, where lung cancer prevalence is high (Chen et al., 2015). The combustion of these four types of coal samples were performed in an experimental room by using a laboratory stove as described by previous report (Tian et al., 2008). We observed signifi- cant amounts of combustion-derived PAHs, hydroxyl- or carboxyl-OPAHs, azaarenes, and carbonyl-OPAHs bound to $\mathrm{PM}_{2.5}$ emitted from the four coal samples. PAHs emitted from coal combustion have been previously characterized (Downward et al., 2014; Wang et al., 2015). Limited information is however available on the concentrations and profiles of OPAHs and azaarenes in emissions from combustion of coal and in indoor environments. Azaarenes are considered as chemical markers for coal combustion, while OPAHs are additionally produced from the photochemical, thermochemical and microbial/enzymatic transformation of emitted PAHs (Bandowe et al., 2014). The largest percentage of particulate matter bound-PACs emitted into the atmosphere of indoor and outdoor environments are bound to the potent $\mathrm{PM}_{2.5}$ fraction (Albinet et al., 2008; Ringuet et al., 2012). Previous studies reported that higher acute toxicity, carcinogenicity and mutagenicity of polar extracts (containing OPAHs and azarenes) from combustion emissions/environmental matrices and some of polar PACs (azarenes and OPAHs) compared to non-polar fractions and individual PAHs (Bandowe et al., 2014; Walgraeve et al., 2010). In addition, oxidative stress induced by OPAHs could be possibly associated with particle toxicity (Benbrahim-Tallaa et al., 2012). Earlier studies on emissions from coal combustion at Xuanwei detected higher mutagenicity (Ames test) in the polar fractions and also demonstrated higher concentrations of dibenz $[a, j]$ acridine (an azaarene) and alkyl-PAHs in smoky coal emissions (Mumford et al., 1987). These studies suggested that polar PACs and alkyl-PAHs could play important roles in the mutagenicity of smoky coals combustion emissions in the region, but to the best of our knowledge most subsequent studies have only continued to focus on the unsubstituted PAHs or benzo $[a]$ pyrene (Tian et al., 2009). Therefore, investigating the role of polar-PAHs and their toxicity in the emissions is essential to understand the causes of lung cancer in Xuanwei.

An epidemiological study showed that coal combustion is associated with development of lung cancer in the Xuanwei region in China, particularly causing EGFR and KRAS mutations in women (Hosgood et al., 2013). To understand the role of EGFR-TKI response in cells exposed to $\mathrm{PM}_{2.5}$ emitted through coal combustion, A549 with wild-type EGFR and HCC827 with EGFR mutation, both of which are commonly used for $E G F R$-associated lung cancer studies, were used in this study (Fujii et al., 2015; Lee et al., 2013). The effects of four $\mathrm{PM}_{2.5}$ samples on cell viability in A549 and $\mathrm{HC}$ C827 were investigated. The dose- and time-dependent experiments showed that A549 were more sensitive than the $\mathrm{HCC} 827$ to $\mathrm{PM}_{2.5}$ 
emitted from the ZJB3 and YTB2 samples, suggesting that $\mathrm{PM}_{2.5}$ emitted from combustion of certain types of coal samples were more toxic for A549 than for HCC827. This could be attributed to the presence of wild-type or mutated EGFR and specific chemical components. In this study, the EGFR-TKI response was further investigated under two experimental conditions, 72-h and two 48-h exposures, which mimicked single and repeated exposures of the coal $\mathrm{PM}_{2.5}$. Single and repeated exposures (with an interval of cell re-growth) were used for generating $>50 \%$ and approximately $50 \%$ reduction in cell viability, respectively. Notably, A549 were sensitive to EGFR-TKI after 72-h exposure to $\mathrm{PM}_{2.5}$ emitted from the DSFZK9 sample and were sensitive to EGFR-TKI after two 24-h exposure to $\mathrm{PM}_{2.5}$ emitted from the four types of coal samples. The change in EGFR-TKI response from insensitive to sensitive in A549 was associated with byproduct $\mathrm{PM}_{2.5}$ emitted from coal combustion can be postulated in here, which confirmed the geographical difference in lung cancer incidence and the use of coal types by Lan and colleagues (Lan et al., 2008). Also, the results are consistent with a previous finding that exposure to wood smoke was associated with response to EGFR-TKIs in lung cancer patients (Arrieta et al., 2012). In another study, biomass burning was an independent factor for increased $E G F R$ mutation frequency and decreased $K R A S$ mutation frequency (Arrieta et al., 2012), which can be a possible explanation about the reduction in cell viability observed in this study. Driver mutations occur in genes that encode signaling proteins that are essential for cell death regulation and proliferation (Pao and Girard, 2011). Lung cancer patients with EGFR mutation show positive response to EGFR-TKI (Chung et al., 2012). EGFR mutations are associated with lung cancer in women in Xuanwei (Hosgood et al., 2013); our results re-affirm the association between EGFR-TKI response and $\mathrm{PM}_{2.5}$ emitted through coal combustion in Xuanwei. Additional experiments will be required to confirm the induction of EGFR mutations in $\mathrm{A} 549$ after exposure to $\mathrm{PM}_{2.5}$ in coal combustion emissions.

Polycyclic aromatic compounds are considered as risk factors for carcinogenesis and have demonstrated to be associated with reduction in cell viability in A549, as shown in this study. A previous study indicated that the coal sample YTB2 contained highest PAHs concentrations and also collected a commune with highest lung cancer rate (Chen et al., 2015; Mumford et al., 1995), whereas the PAHs concentrations produced from DSFZK3 was not from the highest lung cancer rate commune but also from the higher cancer rate commune in Xuanwei. Chrysene and triphenylene, dibenzo[ $[a, h]$ anthracene, benzo $[g h i]$ perylene, azaarenes and carbonyl-OPAHs were correlated to EGFR-TKI regulated cell viability after 72 -h exposure to $\mathrm{PM}_{2.5}$ emitted from the combustion of coal samples; however, the association was not observed in A549 exposed twice for $48 \mathrm{~h}$. The difference in these results could have been caused by induction of EGFR mutations after 72-h exposure to polycyclic aromatic compounds, whereas exposing A549 twice for $48 \mathrm{~h}$ to all $\mathrm{PM}_{2.5}$ samples increased cell response to EGFR-TKI. Three probable human carcinogens indicated by the USEPA (Chrysene and triphenylene, dibenzo $[a, h]$ anthracene and benzo[ghi]perylene) were associated with regulation of cell viability in A549 after 72-h exposure. The underlying mechanisms of $E G F R$ mutations caused by $\mathrm{PM}_{2.5}$ emitted from coal combustion are unclear; however, high amounts of DNA adducts in lung tissue were observed in Chinese women who used coal for cooking purpose (Arrieta et al., 2012). The chemical composition of smoke from coal combustion includes PAHs, which can activate cell proliferation by regulating $E G F R$-related pathways and thymoma viral oncogene homolog serine/threonine protein kinase (Burdick et al., 2003). PAHs and their derivatives can possibly penetrate deep into the lung tissue, inducing peripheral tumors and promoting adenocarcinoma (Devesa et al., 1991). PAH-induced DNA adducts have also been observed in bronchoalveolar lavage sampled from residents in Xuanwei (Mumford et al., 1993). Hosgood et al. (2013) suggested that tumors in tissues other than lungs were induced by coal combustion by-products, such as PAHs, could potentially lead to unique mutational patterns (Hosgood et al., 2013). Mutations in TP53 observed in non-smoking women in Xuanwei were consistent with those induced by PAHs and different from those observed in smoking-related lung cancer tumors (DeMarini et al., 2001). Therefore, the $\mathrm{PM}_{2.5}$-bound azaarenes and carbonyl-OPAHs could be crucial types of chemical compounds in response to EGFR-TKI.

The limitations and future works of this study are to: (1) characterize raw coal samples in order to understand the formation of carcinogens during the coal combustion; (2) investigate the associations between the coal samples and lung cancer risk, in particular the EGFR mutation; (3) conduct animal and cohort studies in order to examine the induction of EGFR mutations after exposure to $\mathrm{PM}_{2.5}$ in coal combustion emissions.

\section{Conclusions}

In conclusion, $\mathrm{PM}_{2.5}$ emitted through coal combustion is possibly associated with response to EGFR-TKI in lung cancer cells. The response is linked to the polycyclic aromatic compounds, specifically for those such as chrysene and triphenylene, dibenzo $[a, h]$ anthracene, benzo[ghi]perylene, azaarenes and carbonyl-OPAHs. The outcome is consistent with a previous study that the highest mutagenic activity is identified in the polar fractions of coal emissions (Mumford et al., 1987). Our findings are to give more evidences about clinical and epidemiological associations between $\mathrm{PM}_{2.5}$ emitted from coal combustion and EGFR-TKI response in lung cancer area of Xuanwei. The results are to further demonstrate the $\mathrm{PM}_{2.5}$ associations with lung cancer under coal combustion conditions at Xuanwei.

\section{Funding}

This study was supported by the Ministry of Science and Technology of Taiwan (104-2621-M-038-002-MY3) and the Taipei Medical University and Shuang Ho Hospital (104TMU-SHH-05).

\section{Authors' contributions}

HCC planned the work and designed the experiments. KFH and CCC composed and finalized the manuscript. LWT, CSC, KHL and ZN performed coal combustion and sample collection experiments. BAMB performed the chemical analysis and composed part of the manuscript. KYL, KJC, CYL and CNL performed the biochemical experiments and provided all clinical comments. All authors analyzed and discussed the results and contributed comments towards the final manuscript.

\section{Conflict of interest}

The authors declare no conflicts of interest.

\section{Acknowledgements}

The authors would like to thank Miss Yi-Syuan Lin, Mrs Yao-Fei Chan and Mr. Michael Wendler for their technical assistances in the laboratory. 


\section{Appendix A. Supplementary data}

Supplementary data related to this article can be found at http://dx. doi.org/10.1016/j.envpol.2016.08.084.

\section{References}

Albinet, A., Leoz-Garziandia, E., Budzinski, H., Villenave, E., Jaffrezo, J.L., 2008. Nitrated and oxygenated derivatives of polycyclic aromatic hydrocarbons in the ambient air of two French alpine valleys: Part 1: concentrations, sources and gas/particle partitioning. Atmos. Environ. 42, 43-54.

Arrieta, O., Campos-Parra, A.D., Zuloaga, C., Aviles, A., Sanchez-Reyes, R., Manriquez, M.E., Covian-Molina, E., Martinez-Barrera, L., Meneses, A., Cardona, A., Borbolla-Escoboza, J.R., 2012. Clinical and pathological characteristics, outcome and mutational profiles regarding non-small-cell lung cancer related to wood-smoke exposure. J. Thorac. Oncol. 7, 1228-1234.

Arrieta, O., Martinez-Barrera, L., Trevino, S., Guzman, E., Castillo-Gonzalez, P., Rios-Trejo, M.A., Flores-Estrada, D., Tellez, E., Gonzalez, C., de la Cruz Vargas, J., Gonzalez-De la Rosa, C.H., Hernandez-Pedro, N., Morales-Barrera, R., De la Garza, J., 2008. Wood-smoke exposure as a response and survival predictor in erlotinib-treated non-small cell lung cancer patients: an open label phase II study. J. Thorac. Oncol. 3, 887-893.

Bandowe, B.A., Meusel, H., Huang, R.J., Ho, K., Cao, J., Hoffmann, T., Wilcke, W., 2014. PM(2). (5)-bound oxygenated PAHs, nitro-PAHs and parent-PAHs from the atmosphere of a Chinese megacity: seasonal variation, sources and cancer risk assessment. Sci. Total Environ. 473-474, 77-87.

Bandowe, B.A., Wilcke, W., 2010. Analysis of polycyclic aromatic hydrocarbons and their oxygen-containing derivatives and metabolites in soils. J. Environ. Qual. 39, 1349-1358.

Barone-Adesi, F., Chapman, R.S., Silverman, D.T., He, X., Hu, W., Vermeulen, R., Ning, B., Fraumeni Jr., J.F., Rothman, N., Lan, Q., 2012. Risk of lung cancer associated with domestic use of coal in Xuanwei, China: retrospective cohort study. BMJ 345, e5414.

Benbrahim-Tallaa, L., Baan, R.A., Grosse, Y., Lauby-Secretan, B., El Ghissassi, F., Bouvard, V., Guha, N., Loomis, D., Straif, K., 2012. Carcinogenicity of diesel-engine and gasoline-engine exhausts and some nitroarenes. Lancet Oncol. 13, 663-664.

Bi, X., Simoneit, B.R.T., Sheng, G., Fu, J., 2008. Characterization of molecular markers in smoke from residential coal combustion in China. Fuel 87, 112-119.

Burdick, A.D., Davis 2nd, J.W., Liu, K.J., Hudson, L.G., Shi, H., Monske, M.L., Burchiel, S.W., 2003. Benzo(a)pyrene quinones increase cell proliferation, generate reactive oxygen species, and transactivate the epidermal growth factor receptor in breast epithelial cells. Cancer Res. 63, 7825-7833.

CDC, 2015. Lung Cancer. https://www.cdc.gov/cancer/lung/statistics/.

Chen, G., Sun, X., Ren, H., Wan, X., Huang, H., Ma, X., Ning, B., Zou, X., Hu, W. Yang, G., 2015. The mortality patterns of lung cancer between 1990 and 2013 in Xuanwei, China. Lung Cancer 90, 155-160.

Chen, K.Y., Chen, J.H., Shih, J.Y., Yang, C.H., Yu, C.J., Yang, P.C., 2010. Octogenarians with advanced non-small cell lung cancer: treatment modalities, survival, and prognostic factors. J. Thorac. Oncol. 5, 82-89.

Chuang, H.C., Cheng, Y.L., Lei, Y.C., Chang, H.H., Cheng, T.J., 2013. Protective effects of pulmonary epithelial lining fluid on oxidative stress and DNA single-strand breaks caused by ultrafine carbon black, ferrous sulphate and organic extract of diesel exhaust particles. Toxicol. Appl. Pharmacol. 266, 329-334.

Chung, K.P., Wu, S.G., Wu, J.Y., Yang, J.C., Yu, C.J., Wei, P.F., Shih, J.Y., Yang, P.C., 2012. Clinical outcomes in non-small cell lung cancers harboring different exon 19 deletions in EGFR. Clin. Cancer Res. 18, 3470-3477.

Dela Cruz, C.S., Tanoue, L.T., Matthay, R.A., 2011. Lung cancer: epidemiology, etiology, and prevention. Clin. Chest Med. 32, 605-644.

DeMarini, D.M., Landi, S., Tian, D., Hanley, N.M., Li, X., Hu, F., Roop, B.C., Mass, M.J., Keohavong, P., Gao, W., Olivier, M., Hainaut, P., Mumford, J.L., 2001. Lung tumor KRAS and TP53 mutations in nonsmokers reflect exposure to PAH-rich coal combustion emissions. Cancer Res. 61, 6679-6681.
Devesa, S.S., Shaw, G.L., Blot, W.J., 1991. Changing patterns of lung cancer incidence by histological type. Cancer Epidemiol. Biomarkers Prev. 1, 29-34.

Downward, G.S., Hu, W., Rothman, N., Reiss, B., Wu, G., Wei, F., Chapman, R.S., Portengen, L., Qing, L., Vermeulen, R., 2014. Polycyclic aromatic hydrocarbon exposure in household air pollution from solid fuel combustion among the female population of Xuanwei and Fuyuan counties, China. Environ. Sci. Technol. 48, 14632-14641.

Fujii, A., Harada, T., Iwama, E., Ota, K., Furuyama, K., Ijichi, K., Okamoto, T., Okamoto, I., Takayama, K., Nakanishi, Y., 2015. Hypermethylation of the CpG dinucleotide in epidermal growth factor receptor codon 790: implications for a mutational hotspot leading to the T790M mutation in non-small-cell lung cancer. Cancer Genet. 208, 271-278.

Hosgood 3rd, H.D., Pao, W., Rothman, N., Hu, W., Pan, Y.H., Kuchinsky, K., Jones, K.D., Xu, J., Vermeulen, R., Simko, J., Lan, Q., 2013. Driver mutations among never smoking female lung cancer tissues in China identify unique EGFR and KRAS mutation pattern associated with household coal burning. Respir. Med. 107, 1755-1762.

IARC, 2010. Household Use of Solid Fues and High-temperature Frying. IARC Monographs on the Evalution of Carcinogenic Risk to Humans. http://monographs.iarc. $\mathrm{fr} / \mathrm{ENG} /$ Monographs/vol95/.

Lan, Q., He, X., Shen, M., Tian, L., Liu, L.Z., Lai, H., Chen, W., Berndt, S.I., Hosgood, H.D., Lee, K.M., Zheng, T., Blair, A., Chapman, R.S., 2008. Variation in lung cancer risk by smoky coal subtype in Xuanwei, China. Int. J. Cancer 123, 2164-2169.

Langer, C.J., 2011. Roles of EGFR and KRAS mutations in the treatment of patients with non-small-cell lung Cancer. P T 36, 263-279.

Lee, H.K., Park, G.B., Kim, Y.S., Song, H., Broaddus, V.C., Hur, D.Y., 2013. Ligation of CM1 enhances apoptosis of lung cancer cells through different mechanisms in conformity with EGFR mutation. Int. J. Oncol. 42, 469-477.

Liu, G.R., Peng, X., Wang, R.K., Tian, Y.Z., Shi, G.L., Wu, J.H., Zhang, P., Zhou, L.D., Feng, Y.C., 2015. A new receptor model-incremental lifetime cancer risk method to quantify the carcinogenic risks associated with sources of particle-bound polycyclic aromatic hydrocarbons from Chengdu in China. J. Hazard Mater 283, 462-468.

Molina, J.R., Yang, P., Cassivi, S.D., Schild, S.E., Adjei, A.A., 2008. Non-small cell lung cancer: epidemiology, risk factors, treatment, and survivorship. Mayo Clin. Proc. 83, 584-594.

Mumford, J.L., He, X.Z., Chapman, R.S., Cao, S.R., Harris, D.B., Li, X.M., Xian, Y.L., Jiang, W.Z., Xu, C.W., Chuang, J.C., et al., 1987. Lung cancer and indoor air pollution in Xuan Wei, China. Science 235, 217-220.

Mumford, J.L., Lee, X., Lewtas, J., Young, T.L., Santella, R.M., 1993. DNA adducts as biomarkers for assessing exposure to polycyclic aromatic hydrocarbons in tissues from Xuan Wei women with high exposure to coal combustion emissions and high lung cancer mortality. Environ. Health Perspect. 99, 83-87.

Mumford, J.L., Li, X., Hu, F., Lu, X.B., Chuang, J.C., 1995. Human exposure and dosimetry of polycyclic aromatic hydrocarbons in urine from Xuan Wei, China with high lung cancer mortality associated with exposure to unvented coal smoke. Carcinogenesis 16, 3031-3036.

Pao, W., Girard, N., 2011. New driver mutations in non-small-cell lung cancer. Lancet Oncol. 12, 175-180.

Ringuet, J., Leoz-Garziandia, E., Budzinski, H., Villenave, E., Albinet, A., 2012. Particle size distribution of nitrated and oxygenated polycyclic aromatic hydrocarbons (NPAHs and OPAHs) on traffic and suburban sites of a European megacity: Paris (France). Atmos. Chem. Phys. 12, 8877-8887.

Shao, L., Hou, C., Geng, C., Liu, J., Hu, Y., Wang, J., Jones, T., Zhao, C., BéruBé, K., 2016. The oxidative potential of PM10 from coal, briquettes and wood charcoal burnt in an experimental domestic stove. Atmos. Environ. 127, 372-381.

Shao, L., Hu, Y., Wang, J., Hou, C., Yang, Y., Wu, M., 2013. Particle-induced oxidative damage of indoor PM10 from coal burning homes in the lung cancer area of Xuan Wei, China. Atmos. Environ. 77, 959-967.

Simoneit, B.R., Bi, X., Oros, D.R., Medeiros, P.M., Sheng, G., Fu, J., 2007. Phenols and hydroxy-PAHs (arylphenols) as tracers for coal smoke particulate matter: source tests and ambient aerosol assessments. Environ. Sci. Technol. 41, 7294-7302.

Tian, L., Lan, Q., Yang, D., He, X., Yu, I.T.S., Hammond, S.K., 2009. Effect of chimneys on indoor air concentrations of PM10 
and benzo[a]pyrene in Xuan Wei, China. Atmos. Environ. 43, 3352-3355.

Tian, L., Lucas, D., Fischer, S.L., Lee, S.C., Hammond, S.K., Koshland, C.P., 2008. Particle and gas emissions from a simulated coal-burning household fire pit. Environ. Sci. Technol. 42, 2503-2508.

Vichai, V., Kirtikara, K., 2006. Sulforhodamine B colorimetric assay for cytotoxicity screening. Nat. Protoc. 1, 1112-1116.

Walgraeve, C., Demeestere, K., Dewulf, J., Zimmermann, R., Van Langenhove, H., 2010. Oxygenated polycyclic aromatic hydrocarbons in atmospheric particulate matter: molecular characterization and occurrence. Atmos. Environ. 44, 1831-1846.

Wang, J., Chen, S., Tian, M., Zheng, X., Gonzales, L., Ohura, T., Mai, B., Simonich, S.L., 2012. Inhalation cancer risk associated with exposure to complex polycyclic aromatic hydrocarbon mixtures in an electronic waste and urban area in South China. Environ. Sci. Technol. 46, 9745-9752. Wang, R., Liu, G., Zhang, J., 2015. Variations of emission characterization of PAHs emitted from different utility boilers of coal-fired power plants and risk assessment related to atmospheric PAHs. Sci. Total Environ. 538, 180-190.

Zhang, Y., Tao, S., Shen, H., Ma, J., 2009. Inhalation exposure to ambient polycyclic aromatic hydrocarbons and lung cancer risk of Chinese population. Proc. Natl. Acad. Sci. U. S. A. 106, 21063-21067. 